\title{
Treatment of uncomplicated UTI in males: a systematic review of the literature
}

\section{Karen Farrell ${ }^{1}$, Meera Tandan², Virginia Hernandez Santiago ${ }^{3}$, Ildiko Gagyor ${ }^{4}$, Anja Maria Braend ${ }^{5}$, Marius Skow ${ }^{5}$, Ingvild Vik ${ }^{5}$, Filip Jansaaker ${ }^{6,7}$, Gail Hayward ${ }^{8}$, Akke Vellinga**}

${ }^{1}$ Department of General Practice, HRB Primary Care Clinical Trials Network Ireland, School of Medicine, National University of Ireland, Galway, Ireland; ${ }^{2}$ Cecil G Sheps Center for Health Services Research, University of North Carolina at Chapel Hill, Chapel Hill, North Carolina, US; ${ }^{3}$ Division of Population and Behavioural Sciences, School of Medicine, University of St Andrews, St Andrews, UK; ${ }^{4}$ Department of General Practice, Universitatsklinikum Wurzburg, Wurzburg, Bavaria, Germany; ${ }^{5}$ The Antibiotic Centre for Primary Care, Department of General Practice, Institute of Health and Society, University of Oslo, Oslo, Norway; ${ }^{6}$ Department of Clinical Microbiology, Rigshospitalet, Kobenhavn, Denmark; ${ }^{7}$ Center for Primary Health Care Research, Lund University, Lund, Sweden; ${ }^{8}$ Nuffield Department of Primary Care Health Science, University of Oxford, Oxford, UK; ${ }^{9}$ School of Medicine, National University of Ireland, Galway, Ireland

\begin{abstract}
Background: Urinary tract infections (UTIs) affect around $20 \%$ of the male population in their lifetime. The incidence of UTls in men in the community is $0.9-2.4$ cases per 1000 aged $<55$ years and 7.7 per 1000 aged $\geq 85$ years.
\end{abstract}

Aim: To evaluate the outcomes of randomised controlled trials (RCTs) comparing the effectiveness of different antimicrobial treatments and durations for uncomplicated UTIs in adult males in outpatient settings.

*For correspondence: akke. vellinga@nuigalway.ie

Competing interest: The authors declare that no competing interests exist.

Received: 13 July 2020

Accepted: 20 August 2020

Published: 03 February 2021

@This article is Open Access: CC BY license (https://creativecommons.org/licenses/by/4.0/)

Author Keywords: male, urinary tract infections, antibiotic treatment, primary health care, randomised clinical trial, review

Copyright (C) 2020, The Authors;

DOI:10.3399/

bjgpopen20X101140
Method: A systematic literature review of RCTs of adult male patients with an uncomplicated UTI treated with oral antimicrobials in any outpatient setting. The outcomes were symptom resolution within 2 weeks of starting treatment, duration until symptom resolution, clinical cure, bacteriological cure, and frequency of adverse events.

Results: From the 1052 abstracts screened, three provided sufficient information on outcomes. One study compared trimethoprim-sulfamethoxazole for 14 days (21 males) with 42 days (21 males). Fluoroquinolones were compared in the two other RCTs: lomefloxacin (10 males) with norfloxacin (11 males), and ciprofloxacin for 7 days (19 males) and 14 days (19 males). Combining the results from the three RCTs shows that for $75 \%$ males with a UTI (76/101) bacteriological cure was reported at the end of the study. Of the 59 patients receiving a fluoroquinolone, 57 (97\%) reported bacteriological and clinical cure within 2 weeks after treatment.

Conclusion: The evidence available is insufficient to make any recommendations in relation to type and duration of antimicrobial treatment for male UTIs. Sufficiently powered RCTs are needed to identify best treatment type and duration for male UTIs in primary care. 


\section{How this fits in}

As the prevalence of urinary tract infection is much higher in females, most of the research has focused on this group. Only three RCTs including a total of 101 males compared different antibiotic treatments for UTI. The clear lack of RCTs and evidence of best practice shows the urgent need for sufficiently powered RCTs to identify best treatment and duration for male UTIs.

\section{Introduction}

UTIs affect around $20 \%$ of the male population in their lifetime. ${ }^{1}$ Incidence of UTI in the community is $0.9-2.4$ cases per 1000 men aged $<55$ years, and up to 7.7 per 1000 in men aged $\geq 85$ years. ${ }^{2}$ UTls are a common cause of bacteraemia and recurrent infections in this population. ${ }^{3,4} \mathrm{UTI}$ are the second most common cause for antibiotic use in primary care. ${ }^{5}$

Treatment guidelines for male UTIs vary. In the UK (the National Institute for Health and Care Excellence [NICE]), Ireland (Strategy for the control of Antimicrobial Resistance in Ireland [SARI]), and Scotland (Intercollegiate Guideline Network [SIGN]) the guidelines recommend trimethoprim or nitrofurantoin as a firstline treatment options for 7 days for male UTIs, or pivmecillinam or ciprofloxacin in case of chronic kidney disease (defined by national cut-off points). The use of secondline antibiotics is assessed based on culture results while also considering any alternative diagnosis. ${ }^{6-8}$ This is similar to Denmark, Sweden, Norway, and Germany, where trimethoprim and nitrofurantoin are also the firstline treatment, in addition to pivmecillinam. ${ }^{9-12}$

Diagnosing and treating a male UTI is challenging. This is partly owing to infrequent presentation and limited evidence available for this acute condition, ${ }^{13}$ and GPs often treat these as complicated UTIs 'to be sure', ${ }^{14}$ which usually involves the use of secondline antimicrobial agents, or longer courses. Up to now, most literature has been focused on research and optimal prescribing for UTIs in females, where treatment guidelines and duration are more clear cut. ${ }^{15-18}$ Even though there is a low incidence of UTIs in men aged $<55$ years, incidence in older men is similar to female UTIs, particularly in patients with prostate problems, those with indwelling catheters, and those who are hospitalised or in longterm care facilities. ${ }^{19,20}$

Prescribing guidelines have inconsistent advice on type and duration of antibiotic courses for male UTIs. ${ }^{21}$ Unlike randomised controlled trials (RCTs) on female UTls, ${ }^{22}$ few RCTs include men with community-acquired UTIs who are treated in primary care. ${ }^{23}$ Symptoms of a typical male UTI include: lower urinary tract irritative symptoms such as urgency, frequency, dysuria, and nocturia. ${ }^{24}$ If not treated timely and appropriately, these symptoms may lead to pyelonephritis (kidney infection), which is characterised by fever, and costovertebral angle tenderness. ${ }^{25}$

This review aims to identify RCTs evaluating the effectiveness and duration of different antimicrobial regimens for uncomplicated UTIs in adult males in an outpatient setting.

\section{Method}

\section{Data source and search strategy}

The Cochrane methodology was adopted to perform a systematic search of the literature. ${ }^{26}$ The search was conducted in MEDLINE, Embase, PubMed and the Cochrane Register of Controlled Trials (CENTRAL) (Cochrane Library and Wiley), and CINAHL (EBSCOhost) from 13 March to 10 April 2019 to identify potentially relevant randomised trials focusing on male UTIs. The search terms included were 'urinary tract infections', 'men', 'male', 'treatment', 'treatment dose', 'duration', 'regimens and therapies', 'antimicrobials', 'antibiotics', 'randomised controlled trial'', 'placebo trials', 'pragmatic trials', and 'RCT'. Further, to simplify the search terms, the following were also searched for: 'urinary tract', 'recurrence', 'uncomplicated', 'acute cystitis for urinary tract infections'; and a specific list of antimicrobials, including 'ciprofloxacin', 'norfloxacin', 'fluoroquinolones', 'nalidixic acid', 'ofloxacin', 'moxifloxacin', 'amoxicillin', 'amoxiclav', 'cephalexin', 'nitrofurantoin', 'fosfomycin', 'trimethoprim', 'trimethoprim/sulfamethoxazole', 'beta-lactam', 'pivampicillin', 'pivmecillinam'. The reference lists of articles identified during the screening process were searched to identify any relevant papers for inclusion.

\section{Screening and eligibility}

All RCTs identified were uploaded to the bibliographic management software (EndNote X9 for Windows). Duplicate studies were removed. All potentially relevant papers identified during the 
screening process were uploaded to Covidence review software management. ${ }^{27}$ Title, abstract, and full-text screening were completed by two researchers independently and articles that remained unclear were discussed collectively until consensus was reached.

\section{Inclusion and exclusion criteria}

Studies included were trials in adult male patients treated with antimicrobials for UTI that reported outcome data on orally administrated antimicrobials comparing different treatments (antimicrobial with antimicrobial or placebo or no treatment or symptomatic) in outpatient settings.

The exclusion criteria were as follows: conditions not consistent with uncomplicated UTI; setting other than primary care; and prophylactic or pharmacokinetic studies.

\section{Data extraction}

Two reviewers independently extracted data from selected full-text articles for inclusion. A standardised form was developed in Covidence. This included the following: year of publication; study population; study period; study site (country); demographic characteristics and number of participants; type, dose and duration of antimicrobial treatments being compared; number of days until resolution of symptoms; recurrence of symptoms; emergence of resistance; and name and types of adverse events that occurred.

\section{Study outcomes}

Outcome data extracted from the eligible RCTs included:

- Relief of symptoms within 2 weeks of starting treatment (defined as 'cure')

- Duration until relief of symptoms

- Relief of symptoms at end of the study (according to study duration time periods: 2 weeks, 30 days, 6 weeks)

- Bacteriological cure

- Recurrence of symptoms (according to study duration time periods: 6 weeks, 5-9 days and 30 days after end of treatment)

- Frequency and type of adverse events

- Antimicrobial resistance (but this was never reported).

\section{Risk of bias assessment}

Quality was assessed by two reviewers independently for each paper using the Cochrane Risk of Bias Tool for Randomised controlled Trials proposed by Higgins et al. ${ }^{28}$ Disagreement about particular studies were resolved by discussion to develop consensus; a third reviewer was available when necessary.

\section{Results}

A total of 1052 titles and abstracts, and 80 full-text papers were reviewed, and three RCTs met the inclusion criteria. Figure 1 represents the PRISMA flow diagram for study inclusion, with full characteristics of included RCTs in Table 1.

An RCT by van Nieuwkoop et al compared 7 days with 14 days of oral ciprofloxacin (500 mg, twice daily) in 357 women and men aged $\geq 18$ years with a diagnosis of febrile UTI in 35 primary care centres and seven emergency departments. ${ }^{29}$ Outcomes included clinical and bacteriological cure and recurrence on day 30 (1-2 weeks after the end of therapy). For this review the authors extracted and shared data from 38 men who were treated in primary care.

Gleckman et $a^{30}$ conducted an RCT in 42 men with recurrent UTI presenting at the outpatient clinic of the Boston Veterans Administration Centre. Patients were randomised to 2 weeks or 6 weeks of trimethoprim-sulfamethoxazole $\left(160 / 800 \mathrm{mg}\right.$, twice daily). ${ }^{30}$ Outcomes reported were bacteriological cure, relapse (therapeutic failure) and recurrence (new infection) up at any time during the follow-up. Follow-up was 6 weeks, with two weekly cultures after the end of treatment.

The third paper was by Iravani who enrolled 727 adults with uncomplicated UTI into 7-10 days lomefloxacin (once daily) or norfloxacin (twice daily) in 27 centres throughout the US. ${ }^{31}$ Outcomes were clinical and bacteriological cure reported 5-9 days after the end of therapy. Results were reported separately for 38 men enrolled in the study for whom outcome data 6 weeks after the end of treatment was available for 21 participants. 


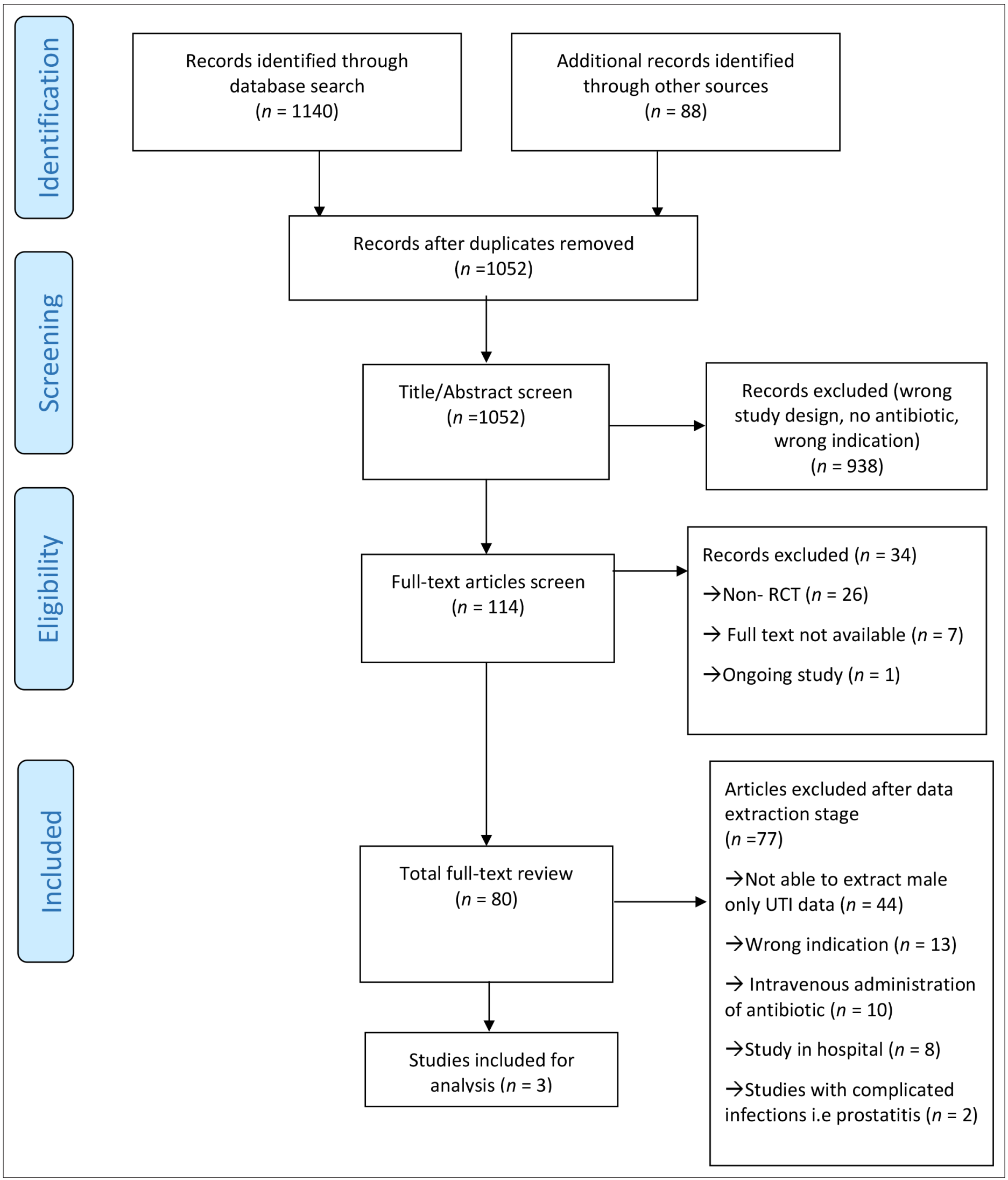

Figure 1 PRISMA flow diagram. RCT = randomised controlled trial; UTI = urinary tract infection. 
Table 1 Descriptive characteristics of studies included

\begin{tabular}{llll}
\hline Characteristics/studies & Gleckman et al ${ }^{30}$ & Iravani $^{31}$ & $\begin{array}{l}\text { van Nieuwkoop et } \\
\text { al }{ }^{29}\end{array}$ \\
\hline Total study duration (months) & 3 & Not available & 3 \\
\hline Total sample & 42 & 727 & 200 \\
\hline Male participants & 42 & 38 (outcome available for 21) & 38 \\
\hline Median patient age, years & 63 & 53 and 45 & 64 \\
\hline Indication & Recurrent UTI & Uncomplicated UTI & Febrile UTI \\
\hline Antimicrobial used & TMP-SMX (160/800 Lomefloxacin (400 mg, once daily), Ciprofloxacin (500 & mg, twice daily) \\
\hline Comorbidities reported & Mg, twice daily) & norfloxacin (400 mg, twice daily) & $\begin{array}{l}\text { Yes: diabetes (9) } \\
\text { urological and heart } \\
\text { conditions }\end{array}$ \\
\hline Study setting and country & $\begin{array}{l}\text { Urology outpatient } \\
\text { clinic, US }\end{array}$ & No Outpatients in medical centres, US Primary care centres, \\
the Netherlands
\end{tabular}

TMP-SMX = trimethoprim-sulfamethoxazole.

The age of participants was not reported consistently across RCTs. Gleckman et a ${ }^{30}$ reported an overall median age of 60 years. Males in the van Nieuwkoop et a ${ }^{29}$ study had a median age of 71 years and 60 years (overall median 64 years) in each group (7 versus 14 days) and Iravani ${ }^{31}$ reported a median age of 53 years and 45 years in each arm of the RCT.

Comorbidities reported were mainly diabetes, which was reported present in 10 patients by Gleckman et $a^{30}$ and nine with diabetes in the van Nieuwkoop et al study ${ }^{29}$ while Iravani ${ }^{31}$ did not report on any comorbidities present.

All outcome data are presented in Table 1; however, the only outcome with sufficient data to allow comparison between RCTs was bacterial cure at the end of therapy.

Table 2 shows an overview of the outcomes of the RCTs. The van Nieuwkoop et al 29 study showed $100 \%$ bacteriological cure for both durations of ciprofloxacin ( 7 days versus 14 days) and $90 \%$ (17 out of 19) and 100\% (19 out of 19) clinical cure for each respectively. Iravani ${ }^{31}$ compared lomefloxacin and norfloxacin and reported 100\% (10 out of 10) and $91 \%$ (10 out of 11) bacteriological cure and 100\% clinical cure for both groups 1 week post-therapy.

Gleckman et a ${ }^{30}$ compared trimethoprim-sulfamethoxazole for 14 days with 42 days with 21 patients in each group, and found all patients had an immediate bacteriological response. In the 14

Table 2 Comparison of UTI clinical and bacteriological cure at the end of treatment, and recurrence

\begin{tabular}{|c|c|c|c|c|c|c|c|c|c|c|}
\hline \multirow[t]{2}{*}{ Studies } & \multirow[t]{2}{*}{ Antimicrobial } & \multirow[t]{2}{*}{ Dose $^{a}$} & \multirow[t]{2}{*}{ Duration } & \multirow[t]{2}{*}{$n$} & \multicolumn{2}{|c|}{ Clinical cure } & \multicolumn{2}{|c|}{ Recurrence } & \multicolumn{2}{|c|}{ Bacteriological cure } \\
\hline & & & & & $n$ & $\%$ & $n$ & $\%$ & $n$ & $\%$ \\
\hline \multirow[t]{2}{*}{$\begin{array}{l}{ }^{30} \mathrm{Gleckman} \\
\text { et al } 1979\end{array}$} & $\begin{array}{c}\text { TMP-SMX+ } \\
\text { Placebo }\end{array}$ & $\begin{array}{c}160 / 800 \\
\mathrm{mg} \mathrm{BD}\end{array}$ & 14 days & 21 & & & 13 & 62 & 6 & 29 \\
\hline & TMP-SMX & $\begin{array}{c}160 / 800 \\
\mathrm{mg} \mathrm{BD}\end{array}$ & 42 days & 21 & & & 6 & 29 & 13 & 62 \\
\hline \multirow[t]{2}{*}{${ }^{31}$ Iravani 1992} & Lomefloxacin & $\begin{array}{c}400 \mathrm{mg} \\
\text { QD }\end{array}$ & $7-10$ days & 10 & 10 & 100 & & & 10 & 100 \\
\hline & Norfloxacin & $\begin{array}{c}400 \mathrm{mg} \\
\mathrm{BD}\end{array}$ & $7-10$ days & 11 & 11 & 100 & & & 10 & 91 \\
\hline \multirow[t]{2}{*}{$\begin{array}{l}{ }^{29} \text { van } \\
\text { Nieuwkoop } \\
\text { et al } 2017\end{array}$} & Ciprofloxacin & $\begin{array}{c}500 \mathrm{mg} \\
\mathrm{BD}\end{array}$ & 7 days & 19 & 17 & 90 & 2 & 11 & 19 & 100 \\
\hline & Ciprofloxacin & $\begin{array}{c}500 \mathrm{mg} \\
\text { BD }\end{array}$ & 14 days & 19 & 19 & 100 & 2 & 11 & $18^{\mathrm{a}}$ & 100 \\
\hline
\end{tabular}

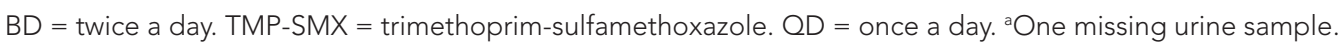


Table 3 Risk of bias assessment

\begin{tabular}{|c|c|c|c|}
\hline & Gleckman et $a^{30}$ & Iravani $^{31}$ & van Nieuwkoop et al ${ }^{29}$ \\
\hline Sequence generation & Low: table of random digits & Low & $\begin{array}{l}\text { Low: randomised stratified per } \\
\text { centre and sex. Computer-generated } \\
\text { randomisation list }\end{array}$ \\
\hline Allocation concealment & Unclear: no information provided & No comment & $\begin{array}{l}\text { Low: treatment allocation completed } \\
\text { after urine culture results. Restricted } \\
\text { access to independent pharmacy }\end{array}$ \\
\hline $\begin{array}{l}\text { Blinding of participants and } \\
\text { personnel for all outcomes }\end{array}$ & $\begin{array}{l}\text { Unclear: no description of the } \\
\text { blinding provided }\end{array}$ & $\begin{array}{l}\text { High: no blinding of the participants or } \\
\text { personnel only investigators }\end{array}$ & Low: double blinding \\
\hline $\begin{array}{l}\text { Blinding of outcome assessors for } \\
\text { all outcomes }\end{array}$ & $\begin{array}{l}\text { Unclear: no description of the } \\
\text { blinding provided }\end{array}$ & $\begin{array}{l}\text { Low: investigators were blinded } \\
\text { through third party. The drugs were } \\
\text { dispensed by an independent third } \\
\text { party to ensure investigator blinding }\end{array}$ & $\begin{array}{l}\text { Low: analysis based on intention to } \\
\text { treat population }\end{array}$ \\
\hline $\begin{array}{l}\text { Incomplete outcome data for all } \\
\text { outcomes }\end{array}$ & $\begin{array}{l}\text { High: data not reported for two } \\
\text { patients in each group suffering } \\
\text { adverse events }\end{array}$ & $\begin{array}{l}\text { High: the main outcome (clinical } \\
\text { recovery) is reported for } 436 / 727 \\
\text { patients only }\end{array}$ & Low \\
\hline Selective outcome reporting & Low & $\begin{array}{l}\text { Unclear: both outcomes assessed } \\
\text { were reported, but no pre-published } \\
\text { protocol is available to control this with } \\
\text { the initial design }\end{array}$ & $\begin{array}{l}\text { Unclear: all outcomes described in } \\
\text { methods chapter are reported }\end{array}$ \\
\hline Other sources of bias & Low & $\begin{array}{l}\text { High: men are just } 5 \% \text { of population } \\
\text { and a subgroup of the study. Dropout } \\
\text { is about } 50 \% \text { for bacteriological cure } \\
\text { and unclear for clinical cure. }\end{array}$ & None identified \\
\hline
\end{tabular}

days group, six (29\%) reached bacteriological cure, 13 (62\%) had recurrence, while in the six-week group, 13 (62\%) and six (29\%) were reported for each outcome.

Combining the results from the three RCTs shows that 76 male patients with UTI (out of 101 patients, 75\%) reported bacteriological cure at the end of the study. Of the 59 patients receiving a fluoroquinolone, 57 (97\%) reported bacteriological and clinical cure within 2 weeks after the end of treatment.

\section{Adverse events}

All three RCTs reported adverse events from antimicrobial treatment, with both Gleckman et al ${ }^{30}$ and van Nieuwkoop et $a^{29}$ reporting separately for male participants. Adverse events were not reported separately for males and females in the Iravani ${ }^{31}$ study. In Gleckman et al, two male patients in the 14day course of trimethoprim group reported five adverse events (chills, sweats and flushing, ${ }^{1}$ transient rash and pruritus ${ }^{1}$ ), while four adverse events (diffuse urticarial, ${ }^{1}$ nausea and vomiting, ${ }^{1}$ elevated serums creatinine ${ }^{2}$ ) were reported for four patients in the group receiving 42 days trimethoprim group. In the van Nieuwkoop et $a^{29}$ study, two patients who were treated with ciprofloxacin for 7 days reported to have developed pyelonephritis, and no adverse events were reported in the 14-day ciprofloxacin group.

\section{Risk of bias assessment}

Risk of bias was low overall for the van Nieuwkoop et $a^{29}$ study, while a high risk of bias was determined for the Iravani ${ }^{31}$ study in three domains: blinding of participants, incomplete outcome data, and other sources of bias (unclear timeframe, allocation, outcome assessment, only $5 \%$ male). In Gleckman et $a^{30}$ risk of bias was unclear for blinding and allocation concealment, while high risk of bias was documented for incomplete outcome data. Table 3 provides an overview of the risk of bias assessment of the included RCTs.

\section{Discussion}

\section{Summary}


This review identified three RCTs evaluating the effectiveness and duration of different antimicrobial regimens for uncomplicated UTIs in adult males. Only three papers met the eligibility criteria after full-text screening and were included in the review, two of which are over 20 years old (Gleckman et al from $1979^{30}$ and Iravani from $1992^{31}$ ).

Iravani ${ }^{31}$ and van Nieuwkoop et $a^{29}$ included both male and female patients, but male-only data was obtained from van Nieuwkoop et al and could be extracted from Iravani's paper. Both RCTs compared a fluoroquinolone (ciprofloxacin or lomefloxacin and norfloxacin) for a course of 7-14 days and observed at least $97 \%$ clinical and bacteriological cure within 2 weeks. However, the total samples size comparing fluoroquinolones is only 59 and is not sufficient to draw any conclusions. The Gleckman et al article focused solely on male participants, and was the only study to use trimethoprim to treat male UTIs. Bacteriological cure was reached in $29 \%$ of the 2 -week treatment group, while the 6-week group reported $62 \%$ at the end of the study. One of the differences with the other RCTs was that Gleckman et al included male patients with a recurrent UTI, but it is difficult to ascertain how this may affect the outcomes or the reliability of the findings because of the small sample size. There is clearly a lack of RCTs to allow comparison of findings, especially in relation to trimethoprim. This is particularly concerning as trimethoprim is the firstline recommendation according to the NICE, ${ }^{6}$ SIGN, ${ }^{7}$ and Danish guidelines. ${ }^{10}$ Considering the age of the paper and its limited sample size, it emphasises the need for more up-to-date and verifiable evidence. Furthermore, no RCTs are available comparing any of the other types and durations of firstline treatments, such as nitrofurantoin or pivmecillinam. The use of fluoroquinolones as done in the other two RCTs, which is only recommended as secondline or for complicated infections, suggests that many GPs consider male UTIs complicated, which may result in suboptimal antibiotic choices or longer courses.

\section{Strengths and limitations}

There is a lack of RCTs comparing antimicrobial treatment options and duration for male UTIs, and most RCTs in this population cover complicated UTIs, ${ }^{32}$ asymptomatic bacteriuria, mixed and recurrent infections, ${ }^{13,33}$ and infections in patients with spinal cord injury, ${ }^{34}$ generally in the hospital setting. ${ }^{19}$

Apart from the lack of evidence to identify the best treatment for male patients presenting with UTI to primary care, the present review also shows the absence of relevant patient outcomes. Duration of symptoms, a relevant outcome for patients, is not reported across groups and RCTs, and no inference about duration until clinical or bacteriological cure could be made.

Owing to low sample size, information on adverse events, even though reported, is not sufficient to make conclusions in relation to type or duration of treatment. However, the variability and extent of adverse events reported in patients treated with trimethoprim in Gleckman et al ${ }^{30}$ is noteworthy, but should not be overstated as it may just reflect good reporting rather than higher risk of adverse events. Pyelonephritis was a serious adverse event reported by two out of 19 patients treated with 7-day ciprofloxacin ${ }^{29}$ and would reflect good reporting as no conclusion can be based on this owing to the low numbers.

\section{Comparison with existing literature}

In a recent systematic review and meta-analysis of RCTs comparing long-term antibiotics for prevention of recurrent UTI in older adults, no RCTs could be identified that compared treatments in the male population. ${ }^{35}$ An observational study by Montelin et $a^{36}$ assessed nitrofurantoin and pivmecillinam for lower UTIs in men, and included patients treated with trimethoprim for comparison. No difference in any clinical outcome was observed between the three antibiotics prescribed. ${ }^{36}$ Similarly, a recent Danish study comparing treatment durations of pivmecillinam in men, suggested that 5 days with pivmecillinam (400 mg, three times a day) is sufficient in male UTI. ${ }^{37}$ These studies were retrospective and should ideally be repeated as a prospective RCT. Interestingly, a register study of male prescribing from Norway found that even though fluoroquinolones and cefalexin were associated with lower antibiotic switch rates than the recommended firstline UTI antibiotics (pivmecillinam, nitrofurantoin, and trimethoprim), the occurrence of switching was so low (7\%) that the current guidelines were considered to be safe. ${ }^{38}$ 


\section{Implications for research and practice}

From this review, it is clear there is a need for larger and more comprehensive RCTs that include improved diagnosis of male UTI, comparison of different types of treatment, as well as their duration and detail of the antimicrobial resistance of the isolated uropathogens. Improved outcome measures, including patient relevant outcomes such as duration of symptoms, should include the recording of symptom scores, which would also improve the understanding of treatment and diagnosis of male UTI. As male UTIs are less frequent, to be able to do such a trial, multiple countries and settings could be included to provide a sufficient sample size and improve the treatment of male UTI.

In conclusion, the evidence available is insufficient to make any recommendations in relation to type and duration of antimicrobial treatment for male UTI. Sufficiently powered RCTs are needed to improve knowledge of male UTI and to identify the best treatment regimen for this population in primary care.

\section{Funding}

No funding was received for this review.

\section{Ethical approval}

This was a systematic review and ethical approval was not required.

\section{Provenance}

Freely submitted; externally peer reviewed.

\section{Acknowledgements}

The authors would like to thank Dr van Nieuwkoop from the Department of Internal Medicine, Haga Teaching Hospital and Department of Infectious Diseases, Leiden University Medical Center, The Netherlands for his generous support by providing the data from his study.

\section{References}

1. Brumfitt W, Hamilton-Miller JM, Gillespie WA. The mysterious 'urethral syndrome'. BMJ 1991; 303(6804): 719-720. DOI: https://doi.org/10.1136/bmj.303.6804.719-c

2. Griebling TL. Urologic diseases in America project: trends in resource use for urinary tract infections in men. $J$ Urol 2005; 173(4): 1288-1294. DOI: https://doi.org/10.1097/01.ju.0000155595.98120.8e

3. Lark RL, Saint S, Chenoweth $C$, et al. Four-Year prospective evaluation of community-acquired bacteremia: epidemiology, microbiology, and patient outcome. Diagn Microbiol Infect Dis 2001; 41(1-2): 15-22. DOI: https:// doi.org/10.1016/S0732-8893(01)00284-X

4. Tal S, Guller V, Levi S, et al. Profile and prognosis of febrile elderly patients with bacteremic urinary tract infection. J Infect 2005; 50(4): 296-305. DOI: https://doi.org/10.1016/j.jinf.2004.04.004

5. Car J. Urinary tract infections in women: diagnosis and management in primary care. BMJ 2006; 332(7533): 94-97. DOI: https://doi.org/10.1136/bmj.332.7533.94

6. National Institute for Health and Care Excellence (NICE). Urinary tract infection (lower): antimicrobial prescribing. Clinical guideline [NG109]. 2018; https://www.nice.org.uk/guidance/ng109/resources/urinary-tract-infection-lowerantimicrobial-prescribing-pdf-66141546350533 (accessed 6 Jan 2021).

7. Scottish Intercollegiate Guideline Network (SIGN). Management of suspected bacterial urinary tract infection in adults: a national clinical guideline. 2012; https://www.sign.ac.uk/media/1051/sign88.pdf (accessed 6 Jan 2021).

8. Strategy for the control of Antimicrobial Resistance in Ireland (SARI). Antimicrobial prescribing guidelines for primary care in Ireland. HSE Antimicrobial Resistance and Infection Control. 2014; http://www.antibioticprescribing. ie/ (accessed 11 Jan 2020).

9. Folkhälsomyndigheten (The Public Health Agency) Sweden. [Treatment recommendations for common infections in primary health care] Behandlingsrekommendationer för vanliga infektioner i öppenvård (in Swedish). 2019; https:// www.folkhalsomyndigheten.se/contentassets/246aa17721b44c5380a0117f6d0aba40/behandlingsrekommend ationer-oppenvard.pdf (accessed 6 Jan 2021).

10. The Capital Region of Denmark. [Complicated cystitis — antibiotic treatment recommendations for primary health care. The Capital Region] Komplicered cysitits — antibiotikavejledning for primaersektorn Region Hovedstaden (in Danish). 2020; https://www.sundhed.dk/sundhedsfaglig/information-til-praksis/hovedstaden/almen-praksis/ laegemidler/antibiotikavejledning/a07-urinveje/kompliceret-cystitis/ (accessed 6 Jan 2021).

11. Wagenlehner FME, Schmiemann G, Hoyme U, et al. S3-guideline for uncomplicated urinary tract infections treatment guidelines compliance. Med Monatsschr Pharm 2011; 34(5): 164-168.

12. Kranz J, Schmidt S, Lebert C, et al. The 2017 update of the German clinical guideline on epidemiology, diagnostics, therapy, prevention, and management of uncomplicated urinary tract infections in adult patients. Part II: therapy and prevention. Urol Int 2018; 100(3): 271-278. DOI: https://doi.org/10.1159/000487645 
13. Griebling TL. Urologic diseases in America project: trends in resource use for urinary tract infections in women. $J$ Urol 2005; 173(4): 1281-1287. DOI: https://doi.org/10.1097/01.ju.0000155596.98780.82

14. Fallon R, Farrell $\mathrm{K}$, Leon $\mathrm{G}$, et al. GPs' attitudes towards the diagnosis and treatment of male urinary tract infections: a qualitative interview study in Ireland. BJGP Open 2019; 3(4): bjgpopen19X101667. DOI: https://doi. org/10.3399/bjgpopen19X101667

15. Christiaens TCM, De Meyere M, Verschraegen G, et al. Randomised controlled trial of nitrofurantoin versus placebo in the treatment of uncomplicated urinary tract infection in adult women. Br J Gen Pract 2002; 52(482): 729-734.

16. Gágyor I, Bleidorn J, Kochen MM, et al. Ibuprofen versus fosfomycin for uncomplicated urinary tract infection in women: randomised controlled trial. BMJ 2015; 351: h6544. DOI: https://doi.org/10.1136/bmj.h6544

17. Gupta K, Hooton TM, Naber KG, et al. International clinical practice guidelines for the treatment of acute uncomplicated cystitis and pyelonephritis in women: a 2010 update by the infectious diseases Society of America and the European Society for microbiology and infectious diseases. Clin Infect Dis 2011; 52(5): e103-e120. DOI: https://doi.org/10.1093/cid/ciq257

18. Vik I, Bollestad M, Grude N, et al. Ibuprofen versus pivmecillinam for uncomplicated urinary tract infection in women - A double-blind, randomized non-inferiority trial. PLoS Med 2018; 15(5): e1002569. DOI: https://doi.org/ 10.1371/journal.pmed.1002569

19. Rowe TA, Juthani-Mehta M. Diagnosis and management of urinary tract infection in older adults. Infect Dis Clin North Am 2014; 28(1): 75-89. DOI: https://doi.org/10.1016/j.idc.2013.10.004

20. Nicolle LE. Urinary tract infections in the older adult. Clin Geriatr Med 2016; 32(3): 523-538. DOI: https://doi.org/ 10.1016/j.cger.2016.03.002

21. Schaeffer EM. Re: urinary tract infection in male veterans: treatment patterns and outcomes. J Urol 2013; 190(4): 1253-1254. DOI: https://doi.org/10.1016/j.juro.2013.06.116

22. Hickling DR, Nitti VW. Management of recurrent urinary tract infections in healthy adult women. Rev Urol 2013; 15(2): 41-48.

23. Ahmed H, Farewell D, Francis NA, et al. Impact of antibiotic treatment duration on outcomes in older men with suspected urinary tract infection: retrospective cohort study. Pharmacoepidemiol Drug Saf 2019; 28(6): 857-866. DOI: https://doi.org/10.1002/pds.4791

24. Jones C, Hill J, Chapple C, Guideline Development Group. Management of lower urinary tract symptoms in men: summary of NICE guidance. BMJ 2010; 340: c2354. DOI: https://doi.org/10.1136/bmj.c2354

25. Schaeffer AJ, Nicolle LE. Urinary tract infections in older men. N Engl J Med 2016; 374(6): 562-571. DOI: https:// doi.org/10.1056/NEJMcp1503950

26. Higgins JPT, Green S. Higgins J, ed. Cochrane Handbook for Systematic Reviews of Interventions. Chichester: The Cochrane Collaboration and John Wiley \& Sons Ltd; 2008.

27. Covidence. Better systematic review management. 2020; https://www.covidence.org/home (accessed 6 Jan 2021).

28. Higgins JPT, Altman DG, Gøtzsche PC, et al. The Cochrane collaboration's tool for assessing risk of bias in randomised trials. BMJ 2011; 343: d5928: d5928: . DOI: https://doi.org/10.1136/bmj.d5928

29. van Nieuwkoop C, van der Starre WE, Stalenhoef JE, et al. Treatment duration of febrile urinary tract infection: a pragmatic randomized, double-blind, placebo-controlled non-inferiority trial in men and women. BMC Med 2017; 15(1): 70. DOI: https://doi.org/10.1186/s12916-017-0835-3

30. Gleckman R, Crowley M, Natsios GA. Therapy of recurrent invasive urinary-tract infections of men. N Engl J Med 1979; 301(16): 878-880. DOI: https://doi.org/10.1056/NEJM197910183011607

31. Iravani A. Efficacy of lomefloxacin as compared to norfloxacin in the treatment of uncomplicated urinary tract infections in adults. Am J Med 1992; 92(4A): S75-S81. DOI: https://doi.org/10.1016/0002-9343(92)90314-2

32. Cattrall JWS, Robinson AV, Kirby A. A systematic review of randomised clinical trials for oral antibiotic treatment of acute pyelonephritis. Eur J Clin Microbiol Infect Dis 2018; 37(12): 2285-2291. DOI: https://doi.org/10.1007/ s10096-018-3371-y

33. Sabbaj J, Hoagland VL, Cook T. Norfloxacin versus co-trimoxazole in the treatment of recurring urinary tract infections in men. Scand J Infect Dis Suppl 1986; 48: 48-53.

34. Dow $G$, Rao $P$, Harding $G$, et al. A prospective, randomized trial of 3 or 14 days of ciprofloxacin treatment for acute urinary tract infection in patients with spinal cord injury. Clin Infect Dis 2004; 39(5): 658-664. DOI: https://doi.org/ $10.1086 / 423000$

35. Ahmed H, Davies F, Francis N, et al. Long-term antibiotics for prevention of recurrent urinary tract infection in older adults: systematic review and meta-analysis of randomised trials. BMJ Open 2017; 7(5): e015233. DOI: https://doi. org/10.1136/bmjopen-2016-015233

36. Montelin $\mathrm{H}$, Forsman K-J, Tängdén T. Retrospective evaluation of nitrofurantoin and pivmecillinam for the treatment of lower urinary tract infections in men. PLoS One 2019; 14(1): e0211098. DOI: https://doi.org/10.1371/ journal.pone.0211098

37. Boel JB, Jansåker F, Hertz FB, et al. Treatment duration of pivmecillinam in men, non-pregnant and pregnant women for community-acquired urinary tract infections caused by Escherichia coli: a retrospective Danish cohort study. J Antimicrob Chemother 2019; 74(9): 2767-2773. DOI: https://doi.org/10.1093/jac/dkz211

38. Skow MAH, Vik I, Høye S. Antibiotic switch after treatment with UTI antibiotics in male patients. Infect Dis 2020 ; 52(6): 405-412. DOI: https://doi.org/10.1080/23744235.2020.1736329 